\title{
Tailor-made thermosets obtained by sequential dual-curing combining isocyanate-thiol and epoxy-thiol click reactions
}

\author{
Francesco Gamardella a, Valentina Sabatini a, b, Xavier Ramis c, Àngels Serra a, \\ a Analytical and Organic Chemistry Dpt., Universitat Rovira i Virgili, C/ Marcellí Domingo s/n Edif. N4, 43007, Tarragona, Spain \\ b Chemistry Dpt, Università degli Studi di Milano, Via Golgi 19, 20133, Milano, Italy \\ c Thermodynamics Laboratory, ETSEIB Universitat Politècnica de Catalunya, Av. Diagonal, 08028, Barcelona, Spain
}

\section{A R T I C L E I N F O}

Keywords:

Thiol

Isocyanate

Epoxy

Sequential dual-curing

Thermosets

\begin{abstract}
A B S T R A C T
In this work, a new family of thermosets based on thiol-isocyanate-epoxy networks has been prepared via sequential dual-curing methodology where both reactions are activated by temperature. The sequential dual behaviour of the new system proposed here is based on the faster reaction kinetic of the first curing stage, i.e. the isocyanate-thiol coupling, which proceeds at a relatively low temperature, compared to the second stage, i.e. the epoxy-thiol reaction, between the remaining thiol functionalities and the epoxy groups that takes place at a higher temperature. Furthermore, the effect of using different aliphatic isocyanates was investigated. Both reactions have a click character and the intermediate/final materials show a wide range of properties depending on the relative contribution of both curing stages thanks to the selected ratio between the isocyanate and epoxy groups. The new thermosets obtained were characterized from the thermal and dynamic mechanical point of view, resulting excellent candidates as smart materials due to their narrow transitions, which favours fast and controlled changes in their macromolecular features.
\end{abstract}

\section{Introduction}

Thermosets have been known for over a hundred years and, nowadays these materials cover a broad range of applications in several high added-value sectors, i.e. aeronautical engineering, automotive industry, optoelectronics and coatings [1-4]. Furthermore, the success of these materials depends in part on the treatment techniques used to improve thermosets properties and, fortunately, the scientific research continues to thrive.

Nowadays, the dual-curing methodology represents an efficient way to enhance thermosets processing features. A dual-curing process is a combination of two different polymerization routes that can take place sequentially or simultaneously [5]. Sequential dual-curing systems are characterized by noteworthy improvements in terms of process design and control of the formed network [6].

In this kind of synthetic methodology, materials can be partially cured before their processing, storage or assembly; on the other side, their final features can be attained whenever desired by means of thermal or UV-light sources to cure the resins completely. The different contribution of both curing reactions and the properties of the intermediate material can be easily controlled by changing the composition of the formulation, as well as cure technical parameters, i.e. the time and the reaction temperature [7]. Up to now, sequential curing systems are being used in several fields where tailored materials and flexible processes are mandatory, e.g. shape-memory materials, adhesive coatings, holography and lithography [8-12].

The exploration of different processing routes does not represent the end of thermosets development cycle, but it marks the beginning of a new generation of materials that grows with each new monomer or with new proposed combinations of them. In this contest, despite poly(thiourethane)s (PTU) are widely used materials in optical applications thanks to their satisfactory mechanical, physical and optical features, PTU synthetic routes that lead to their formulation have not been widely studied as in the case of their oxygen analogs, poly(urethane)s (PU) $[13,14]$.

Thiol-isocyanate coupling reactions to form thermosets have aroused recently some interest. For example Shin et al. reported a base catalysed thiol-isocyanate curing exploiting the use of different thiols

\footnotetext{
* Corresponding author.

Email address: angels.serra@urv.cat (À. Serra)
} 
Table 1

Composition of the pure and dual formulations prepared.

\begin{tabular}{lllll}
\hline Sample & S4 (wt \%) & DGEBA (wt \%) & IPDI (wt \%) & HDI (wt \%) \\
\hline DGEBA_r_0 & 41.8 & 58.2 & - & - \\
IPDI_r_1 & 52.4 & - & 47.6 & - \\
HDI_r_1 & 59.2 & - & - & 40.8 \\
IPDI_r_0.2 & 43.5 & 48.5 & 7.9 & - \\
IPDI_r_0.5 & 46.5 & 32.4 & 21.1 & - \\
IPDI_r_0.8 & 49.8 & 13.9 & 36.3 & - \\
HDI_r_0.2 & 44.4 & 49.5 & - & 6.1 \\
HDI_r_0.5 & 49.0 & 34.1 & - & 16.9 \\
HDI_r_0.8 & 54.7 & 15.2 & - & 30.1 \\
\hline
\end{tabular}

in combination with isophorone diisocyanate (IPDI) and Gamardella et al. described the preparation and characterization of a new PTU thermoset family combining thiols with different kinds of aliphatic isocyanates by using latent catalysts that allows the control of the process $[15,16]$. However, only few works about PTU-based networks obtained via sequential dual-curing methodologies are reported until now in the scientific literature.

Sequential thiol-isocyanate and thiol-ene/acrylate reactions are the most common dual curing procedures studied [17]. Bowman et al. reported the preparation of thiol-isocyanate-ene networks based on two independent thiol-click reaction mechanisms: a thiol-alkene free radical photopolymerization and a base catalysed thiol-isocyanate anionic reaction [18]. Matsushima et al. described thiol-isocyanate-acrylate ternary networks formed by the combination of thiol-isocyanate coupling, thiol-acrylate Michael addition and acrylate homopolymerization [19]. These results suggest the high potentiality of this type of networks, obtained through dual-curing processes, being the key of its success the specialized engineering of manufacturing these materials.

Thus, taking all of this into account, in the present publication we report the preparation and characterization of a new family of thermosets based on thiol-isocyanate-epoxy networks where both reactions are activated by temperature. The sequential dual character of this curing system relies on the faster reaction kinetic of the isocyanate-thiol coupling that occurs at a relatively low temperature, compared to the epoxy-thiol reaction between the remaining thiol groups and the epoxy that takes place at a higher temperature $[8,16]$. The extent of the first curing step is controlled by the equivalent ratio between the isocyanate and thiol, $r_{N C O}$, which also controls the intermediate and final materials properties. It should also be noticed that both reactions have a click character implying that they are specific, without the formation of undesired by-products, and therefore they lead to homogeneous networks. In general, this type of thermosets is adequate to be applied as smart materials, since they have narrow transitions, which allows quick movements and a rapid change in their properties.

To this purpose, a reactive system containing a thiol crosslinker (pentaerythritol tetrakis(3-mercaptopropionate), S4), a diisocyanate monomer (isophorone diisocyanate (IPDI) or hexamethylene diisocyanate (HDI)) and an epoxy resin (diglycidyl ether of bisphenol A, DGEBA) was studied. 1-Methylimidazole (1MI) was used as the catalyst and its effect in terms of different loadings on curing process was investigated. Both diisocyanates have been selected since they have different reactivity and their structure leads to materials with different characteristics.

The kinetics of both curing stages and the conversion achieved were studied by differential scanning calorimetry (DSC) and Fourier transform infrared spectroscopy (FTIR). Intermediate materials were characterized by calorimetry and fully cured samples by DSC, thermal dynamo mechanical (DMA) and thermogravimetric (TGA) analyses. The good conformability of these materials has been put in evidence.

\section{Experimental part}

\subsection{Materials}

1-Methylimidazole (1MI), pentaerythritol tetrakis (3-mercaptopropionate) (S4, >95\%, $122.17 \mathrm{~g} / \mathrm{eq}$ ), isophorone diisocyanate (IPDI, 98\%, $111.14 \mathrm{~g} / \mathrm{eq}$ ) and hexamethylene diisocyanate (HDI, $>99 \%, 84.10 \mathrm{~g} / \mathrm{eq}$ ) were supplied from Sigma Aldrich and used without further purification. Diglycidyl ether of bisphenol A (DGEBA, $170.21 \mathrm{~g} / \mathrm{eq}$ ) was supplied by Hexion Specialty Chemicals and dried in vacuum for $2 \mathrm{~h}$ at $80^{\circ} \mathrm{C}$ before use.

\subsection{Samples preparation}

To investigate which is the best amount of catalyst to get duality, IPDI and HDI were alternatively mixed with S4 and DGEBA using a fixed ratio between the molar equivalents of isocyanate and thiol comonomers $\left(r_{N C O}\right)$ of $0.5 e q_{N C O} / e q_{t}$, and changing the $1 \mathrm{MI}$ amount in the proportions $0.1,0.05$ or 0.025 phr (parts of catalyst for hundred parts of monomers mixture). Once selected the proportion of $0.025 \mathrm{phr}$ of 1MI, samples were prepared varying the $r_{N C O}$ as 0.2 and $0.8 e q_{N C O} / e q_{t}$. The pure S4-isocyanate $\left(r_{N C O}=1\right)$ and S4-DGEBA $\left(r_{N C O}=0\right)$ formulations were also studied. The theoretical critical gelation ratio, $r_{c}$, was calculated using the Flory-Stockmayer equation (Eq. (1)) in a similar manner as in a previous work, where $f_{N C O}$ and $f_{t}$ are the average functionalities of isocyanate $\left(f_{N C O}=2\right)$ and S4 $\left(f_{t}=4\right)$ comonomers [20]. Both families of thermosets studied are characterized by a $r_{c}=0.33$.

$r_{c}=\frac{1}{(f N C O-1) \times(f t-1)}$,

Formulations were prepared by adding the components into a $10 \mathrm{~mL}$ glass vial by the following order: i) 1MI; ii) S4; iii) DGEBA and iv) isocyanate. The whole mixture was manually stirred, and analysed immediately after. Table 1 shows the compositions of pure and dual

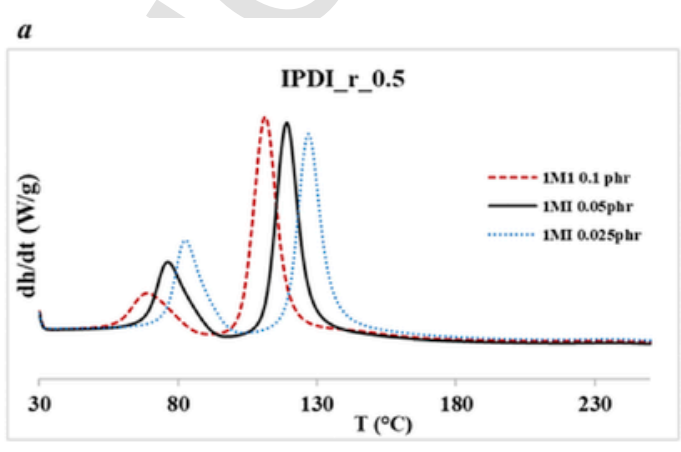

$b$

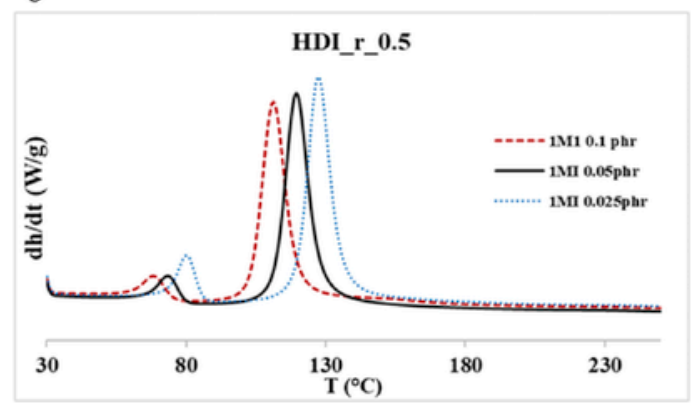

Fig. 1. DSC thermograms corresponding to the dynamic curing at $10^{\circ} \mathrm{C} / \mathrm{min}$ with different $1 \mathrm{MI}$ amounts of a) IPDI_r_0.5 and b) HDI_r_0.5. 
Table 2

Calorimetric data of IPDI_r_0.5 and HDI_r_0.5 curing using 0.1-0.05-0.025 phr of 1MI.

\begin{tabular}{llllllll}
\hline Sample & $\begin{array}{l}1 \mathrm{MI} \\
(\mathrm{phr})\end{array}$ & $\begin{array}{l}\Delta H_{N C O}{ }^{\mathrm{a}} \\
(\mathrm{J} / \mathrm{g})\end{array}$ & $\begin{array}{l}\Delta H_{N C O}{ }^{\mathrm{a}} \\
(\mathrm{kJ} /\end{array}$ & $\begin{array}{l}\Delta H_{e} \mathrm{~b} \\
\mathrm{eq})\end{array}$ & $\begin{array}{l}\Delta H_{e}{ }^{\mathrm{b}} \\
(\mathrm{kJ} / \mathrm{g}) \\
\mathrm{eq})\end{array}$ & $\begin{array}{l}T_{\text {peak, }} \\
{ }^{N}{ }^{\mathrm{c}} \\
\left({ }^{\circ} \mathrm{C}\right)\end{array}$ & $\begin{array}{l}T_{\text {peak,e }}{ }^{\mathrm{d}} \\
\left({ }^{\circ} \mathrm{C}\right)\end{array}$ \\
\hline IPDI_r_0.5 & 0.1 & 60.2 & 31.7 & 247.7 & 130.2 & 69.1 & 112.8 \\
& 0.05 & 90.9 & 47.8 & 248.7 & 130.7 & 76.6 & 120.4 \\
& 0.025 & 103.7 & 54.5 & 252.3 & 132.6 & 82.7 & 127.5 \\
HDI_r_0.5 & 0.1 & 24.6 & 12.3 & 252.3 & 125.8 & 68.4 & 112.3 \\
& 0.05 & 27.8 & 13.8 & 263.4 & 131.4 & 73.4 & 121.0 \\
& 0.025 & 40.1 & 19.6 & 272.5 & 135.9 & 80.3 & 128.8 \\
\hline
\end{tabular}

a Enthalpy released in the thiol-isocyanate process by gr of mixture and by equivalent of isocyanate.

b Enthalpy released in the thiol-epoxy process by gr of mixture and by equivalent of epoxide.

c Temperature of the maximum of the peak of the thiol-isocyanate process.

d Temperature of the maximum of the peak of the thiol-epoxy process.

formulations. Since S4 and DGEBA are present in all compositions, the dual samples were coded as " $x_{-} r_{-} y$ ", where $x$ indicates the isocyanate used and $y$ is the $\mathrm{r}_{\mathrm{NCO}}$ chosen; in the case of pure formulations, $x$ indicates if DGEBA or IPDI/HDI were selected. As an example, IPDI_r_0.5 is a formulation in which one half of S4 equivalents react with IPDI isocyanate equivalents and the other half react with DGEBA epoxy equivalents.

Fully cured samples for dynamic mechanical (DMA) and thermogravimetric (TGA) analyses were prepared in an open mould, with dimensions of $1.5 \times 5 \times 15 \mathrm{~mm}^{3}$, made by PTFE to avoid the presence of bubbles and to facilitate the samples release. The liquid formulations were poured into the mould and kept in an oven at $60^{\circ} \mathrm{C}$ for $60 \mathrm{~min}$ in the case of IPDI-based compositions and for $40 \mathrm{~min}$ for HDI formulations (stage 1); after which the samples were post-cured at $120^{\circ} \mathrm{C}$ for $120 \mathrm{~min}$ (stage 2) and then slowly cooled slowly to room temperature inside the oven. The curing times reported were optimized according to Fourier transform infrared spectroscopy (FTIR) and differential scanning calorimetry (DSC) analyses described in the following paragraphs. The samples were polished with sandpaper to obtain uniform final dimensions.

\subsection{Characterization techniques}

DSC analyses were carried out on a Mettler DSC-821 instruments calibrated using indium (heat flow calibration) and zinc (temperature calibration) standards. Samples of approximately $8-10 \mathrm{mg}$ were placed in aluminium pans with pierced lids and analysed in nitrogen atmosphere with a gas flow of $50 \mathrm{~cm}^{3} / \mathrm{min}$. Dynamic studies between 30 and $250{ }^{\circ} \mathrm{C}$ with a heating rate of $10^{\circ} \mathrm{C} / \mathrm{min}$ were performed to characterize the curing process and measure the final glass transition temperature $\left(T_{g}\right)$. Dynamic curing tests were also performed with heating rates of 2 , 5 and $20^{\circ} \mathrm{C} / \mathrm{min}$. The reaction enthalpy $(\Delta h)$ was integrated from the calorimetric heat flow signal $(d h / d t)$ using a straight baseline with the

$a$

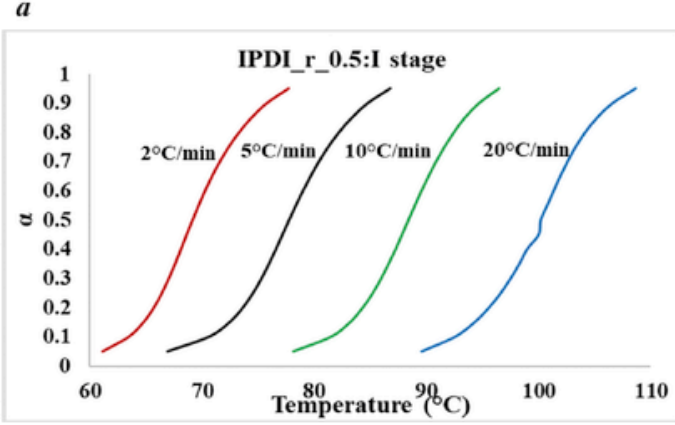

help of the STARe software. Due to the high reactivity of thiol-isocyanate reaction, the curing begins at room temperature during the preparation of the mixtures. In consequence, the relative conversions were used instead of absolute conversion [21]. The calorimetric relative conversion at a given temperature was determined as reported in Eq. (2)).

$\mathrm{x}_{D S C}=\frac{\Delta h_{T}}{\Delta \mathrm{h}_{t o t}}$,

where $\Delta h_{T}$ is the heat released up to $T$ and $\Delta h_{\text {tot }}$ the total reaction heat evolved in a dynamic run.

The $T_{g} \mathrm{~s}$ of the intermediate materials were determined with the following procedure: i) isothermal curing at $60^{\circ} \mathrm{C}$ until the first reaction comes to the end ( $40 \mathrm{~min}$ for HDI and $60 \mathrm{~min}$ for IPDI mixtures); ii) dynamic heating from -50 to $100^{\circ} \mathrm{C}$ at $10^{\circ} \mathrm{C} / \mathrm{min}$. Furthermore, intermediate and final materials $T_{g} \mathrm{~s}$ were estimated using the Fox copolymer rule given by Eqs. (3) and (4) respectively [22].

$\frac{1}{T g, 1}=\frac{w N C O-\mathrm{t}}{T \infty g(N C O-\mathrm{t})}+\frac{1-w N C O-\mathrm{t}}{\mathrm{T} 0 \mathrm{~g}(\mathrm{e}-\mathrm{t})}$,

$\frac{1}{T g, 2}=\frac{w N C O-\mathrm{t}}{T \operatorname{cog}(N C O-\mathrm{t})}+\frac{1-w N C O-\mathrm{t}}{T \operatorname{cog}(\mathrm{e}-\mathrm{t})}$,

where $T_{g, 1}$ and $T_{g, 2}$ are the $T_{g} \mathrm{~s}$ of intermediate material and final thermoset for any $r_{N C O}$ considered. $w_{N C O-t}$ is the weight fraction of the isocyanate plus the part of thiol which participate in the first curing step; $T_{g(\mathrm{e}-\mathrm{t})}^{0}$ is the experimental $T_{g}$ of the uncured epoxy-thiol system; $T_{g(\mathrm{NCO}-\mathrm{t})}^{\infty}$ and $T_{g(\mathrm{e}-\mathrm{t})}^{\infty}$ are the $T_{g}$ of the cured isocyanate-thiol and epoxy-thiol systems, respectively.

To monitor the dual-curing process and to quantitatively determine the degree of cure, a FTIR spectrometer Bruker Vertex 70 with an attenuated total reflection accessory with thermal control and a diamond crystal (Golden Gate Heated Single Reflection Diamond ATR Specac-Teknokroma) and equipped with a mid-band liquid nitrogen-cooled mercury-cadmium-telluride (MCT) detector was used. Real-time spectra were collected in absorbance mode with a resolution of $4 \mathrm{~cm}^{-1}$ in the wavelength range 4000 to $600 \mathrm{~cm}^{-1}$ averaging 20 scans for each spectrum. The first step of the dual-curing process was conducted at $60^{\circ} \mathrm{C}$ and the second one at $120^{\circ} \mathrm{C}$. The characteristic absorbance peak of the isocyanate at $2280 \mathrm{~cm}^{-1}$ (vibration of $-\mathrm{N}$ $=\mathrm{C}=\mathrm{O}$ groups) was used to monitor the conversion of the isocyanate group during thiol-isocyanate reaction [23]. The disappearance of the absorbance peak at $915 \mathrm{~cm}^{-1}$ was used to monitor the reaction of epoxy groups [24]. Absorbance of each scanned sample were normalized with that of the S4-ester group at $1730 \mathrm{~cm}^{-1}$ [25]. Isocyanate groups conversion $\left(X_{N C O}\right)$ and epoxy groups conversion $\left(X_{e}\right)$ were calculated by Eqs. (5) and (6).

b

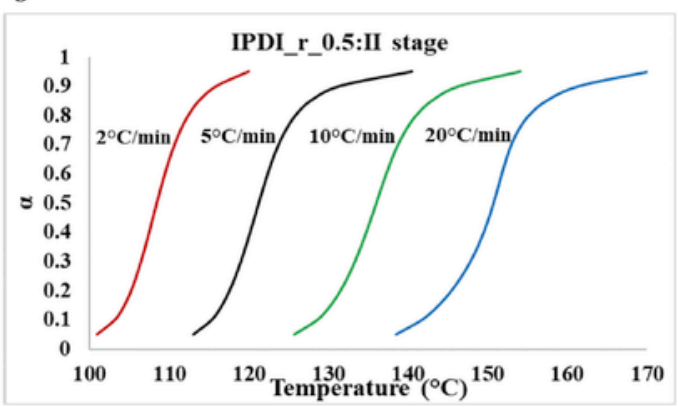

Fig. 2. Degree of conversion versus temperature for IPDI_r_o.5. formulation with $0.025 \mathrm{phr}$ of $1 \mathrm{MI}$ a) first and b) second stages. 
Table 3

Kinetic parameters of dynamic curing obtained by DSC of IPDI_r_ 0.5 formulation.

\begin{tabular}{|c|c|c|c|c|c|c|c|}
\hline Stage & $\alpha^{\mathrm{a}}$ & $\begin{array}{l}E^{\mathrm{b}}(\mathrm{kJ} / \\
\mathrm{mol})\end{array}$ & $\begin{array}{l}\ln [A R / \\
g(\alpha) E] \\
\left(\mathrm{K}^{-1} \cdot \mathrm{s}^{-1}\right)\end{array}$ & $r^{c}$ & $\begin{array}{l}\ln A^{\mathrm{d}} \\
\left(\mathrm{s}^{-1}\right)\end{array}$ & $k^{\mathrm{e}}$ & $\begin{array}{l}d \alpha / d t^{f} \\
\left(s^{-1}\right)\end{array}$ \\
\hline \multirow[t]{9}{*}{ first } & 0.1 & 72.49 & 15.11 & 0.990 & 23.43 & 1.07 & 0.64 \\
\hline & 0.2 & 72.25 & 14.81 & 0.991 & 23.38 & 1.10 & 0.97 \\
\hline & 0.3 & 71.66 & 14.49 & 0.992 & 23.21 & 1.12 & 1.18 \\
\hline & 0.4 & 71.34 & 14.29 & 0.992 & 23.12 & 1.14 & 1.31 \\
\hline & 0.5 & 71.47 & 14.25 & 0.993 & 23.19 & 1.16 & 1.36 \\
\hline & 0.6 & 71.94 & 14.32 & 0.993 & 23.36 & 1.19 & 1.34 \\
\hline & 0.7 & 72.83 & 14.52 & 0.993 & 23.66 & 1.21 & 1.23 \\
\hline & 0.8 & 74.03 & 14.80 & 0.993 & 24.05 & 1.21 & 1.00 \\
\hline & 0.9 & 75.39 & 15.07 & 0.993 & 24.46 & 1.18 & 0.61 \\
\hline \multirow[t]{9}{*}{ second } & 0.1 & 70.13 & 11.31 & 0.997 & 19.78 & 0.06 & 0.04 \\
\hline & 0.2 & 67.83 & 10.45 & 0.996 & 19.08 & 0.06 & 0.06 \\
\hline & 0.3 & 66.35 & 9.91 & 0.996 & 18.64 & 0.06 & 0.08 \\
\hline & 0.4 & 65.63 & 9.62 & 0.996 & 18.43 & 0.06 & 0.09 \\
\hline & 0.5 & 65.49 & 9.52 & 0.996 & 18.40 & 0.07 & 0.10 \\
\hline & 0.6 & 65.75 & 9.54 & 0.996 & 18.49 & 0.07 & 0.10 \\
\hline & 0.7 & 66.13 & 9.58 & 0.997 & 18.61 & 0.07 & 0.09 \\
\hline & 0.8 & 65.59 & 9.43 & 0.997 & 18.53 & 0.07 & 0.07 \\
\hline & 0.9 & 63.69 & 8.49 & 0.999 & 17.64 & 0.06 & 0.04 \\
\hline
\end{tabular}

a Conversion degree.

b Activation energy.

c Correlation coefficient

d Pre-exponential factor calculated using kinetic modelA3 andA4 for the 1stand 2ndstage, respectively.

e Rate constant calculated by Arrhenius equation

f Reaction rate calculated by Eq. (7).

$\mathrm{x}_{N C O}=1-\frac{\mathrm{A} 2280}{\mathrm{~A} 2280,0}$,

$x_{e}=1-\frac{\mathrm{A} 915}{\mathrm{~A} 915,0}$,

where $A_{2280}$ and $A_{2280,0}$ are the normalized absorbances of the isocyanate peak at $2280 \mathrm{~cm}^{-1}$ at a given reaction time and at the beginning of the curing process, respectively and $A_{915}$ and $A_{915,0}$ the normalized absorbances of the epoxy peak at $915 \mathrm{~cm}^{-1}$ at the same time than isocyanate peak.

The thermomechanical properties were evaluated using DMA Q800 (TA Instrument) equipped with a three-point bending clamp. Prismatic rectangular samples of $1.5 \times 5 \times 15 \mathrm{~mm}^{3}$ were analysed from 30 to $150{ }^{\circ} \mathrm{C}$, at $1 \mathrm{~Hz}, 0.1 \%$ strain and with a heating rate of $3{ }^{\circ} \mathrm{C} / \mathrm{min}$. The Young modulus were defined under flexural conditions at $30^{\circ} \mathrm{C}$ with a force ramp rate of $1 \mathrm{~N} / \mathrm{min}$.

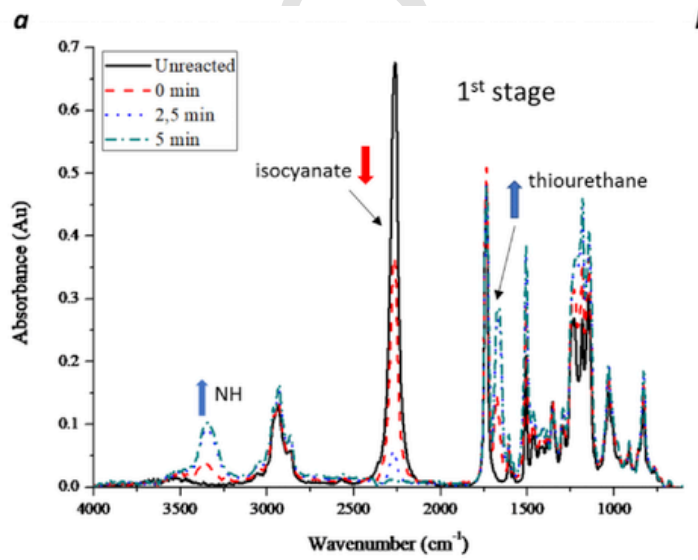

TGA analyses were carried out with a Mettler Toledo TGA2 thermo-balance. Cured samples, weighting around $10 \mathrm{mg}$, were degraded between 30 and $600^{\circ} \mathrm{C}$ at a heating rate of $10^{\circ} \mathrm{C} / \mathrm{min}$ in $\mathrm{N}_{2}$ atmosphere with a flow of $50 \mathrm{~cm}^{3} / \mathrm{min}$.

\section{Theoretical part}

In non-isothermal kinetics of heterogeneous condensed phase reactions, it is usually accepted that the reaction rate is given by Eq. (7) $[26,27]$.

$\frac{d \alpha}{d t}=\beta \frac{d \alpha}{d T}=\mathrm{A} \exp \left(-\frac{\mathrm{E}}{R T}\right) \mathrm{f}(\alpha)$

where $\alpha$ is the degree of conversion, $T$ temperature, $t$ time, $f(\alpha)$ the differential conversion function, $R$ the gas constant, $\beta$ the linear constant heating rate $\beta=\mathrm{d} T / \mathrm{d} t$ and $A$ and $E$ the pre-exponential factor and the activation energy given by the Arrhenius equation.

By integrating Eq. (7), in non-isothermal conditions, the integral rate equation, so-called temperature integral, may be expressed as Eq. (8).

$\mathrm{g}(\alpha)=\int_{0}{ }_{0}^{\alpha} \frac{d \alpha}{\mathrm{f}(\alpha)}=\frac{A}{\beta} \int_{0}^{\mathrm{T}} \mathrm{e}^{-(\mathrm{E} / R T)} d T$,

where $g(\alpha)$ is the integral conversion function.

By using the Coats-Redfern approximation to solve Eq. (8) and considering that $2 \mathrm{RT} / \mathrm{E}$ is much lower than 1, the Kissinger-Akahira-Sunose (KAS) equation (Eq. (9)) may be written [28-30]:

$\ln \left(\frac{\beta}{\mathrm{T}^{2}}\right)=\ln \left[\frac{\mathrm{AR}}{\mathrm{g}(\alpha) \mathrm{E}}\right]-\frac{\mathrm{E}}{R T}$,

For each conversion degree, the linear plot of $\ln \left(\beta / T\right.$ [2]) versus $T^{-1}$ enables $E$ and $\ln [A R / g(\alpha) E]$ to be determined from the slope and the intercept. Iso-conversional kinetic parameters were obtained in this work by using Eq. (9). If the reaction model, $g(\alpha)$, is known, the corresponding pre-exponential factor can be calculated for each conversion.

Rearranging Eq. (9), the Coats-Redfern equation can be written as Eq. (10) [31].

$\ln \left(\frac{\mathrm{g}(\alpha)}{\mathrm{T}^{2}}\right)=\ln \left[\frac{\mathrm{A} \mathrm{R}}{\beta E}\right]-\frac{\mathrm{E}}{R T}$,

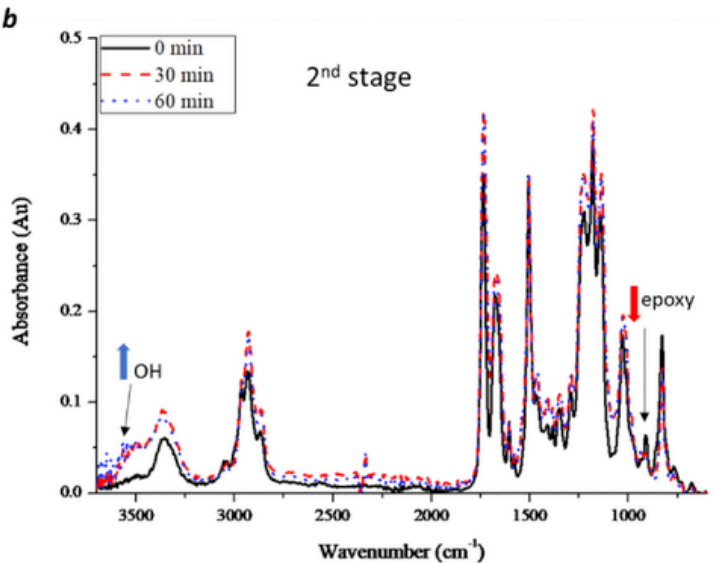

Fig. 3. Evolution of the FTIR spectra during curing of HDI_r_o.5 mixture at a) $60{ }^{\circ} \mathrm{C}$, for 5 min during the 1 st stage of curing and b) $120^{\circ} \mathrm{C}$, for 60 min during 2 nd stage of curing. 


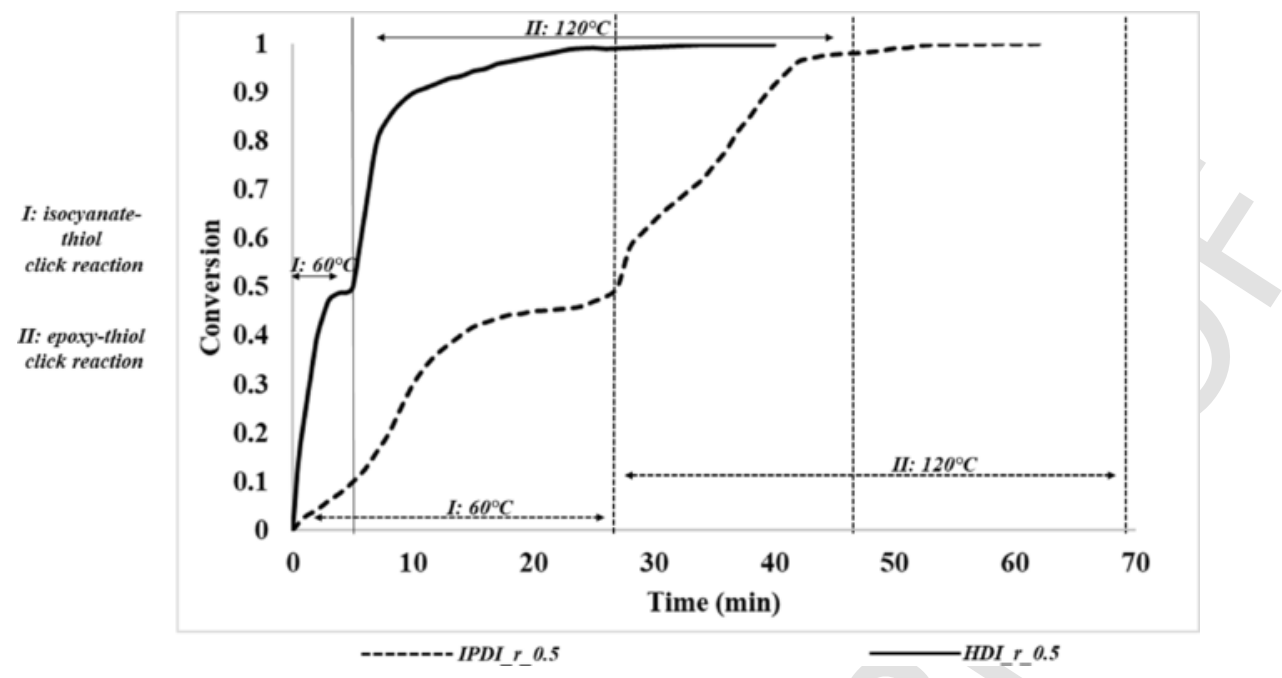

Fig. 4. FTIR isocyanate and epoxy conversion during isothermal curing at $60^{\circ} \mathrm{C}$ (stage I) and at $120^{\circ} \mathrm{C}$ (stage II) for IPDI_r_o.5 and HDI_r_05 formulations.

$a$

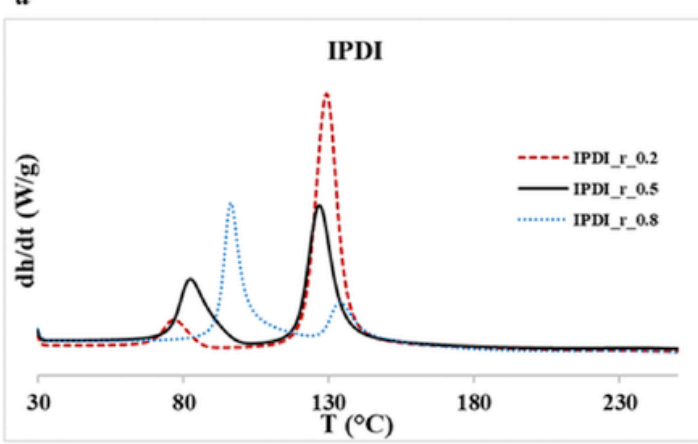

b

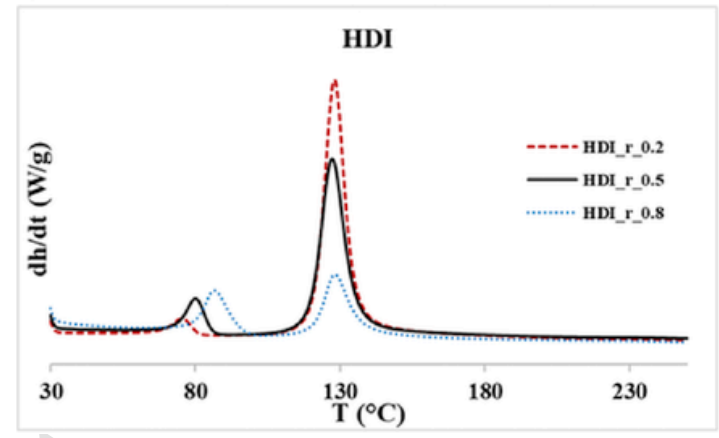

Fig. 5. DSC thermograms corresponding to the dynamic curing at $10^{\circ} \mathrm{C} / \mathrm{min}$ of different compositions of a) IPDI and b) $\mathrm{HDI}$ formulations.

Table 4

Calorimetric data for both stages and theoretical and experimental $T_{g, 1}$ and $T_{g, 2}$.

\begin{tabular}{|c|c|c|c|c|c|c|c|c|}
\hline & $1^{\text {st }}$ stage & & $2^{\text {nd }}$ stage & & $1^{\text {st }}$ stage & & $2^{\text {nd }}$ stage & \\
\hline Sample & $\Delta H_{N C O}(\mathrm{~J} / \mathrm{g})$ & $\Delta H_{N C O}(\mathrm{~kJ} / \mathrm{eq})$ & $\Delta H_{e}(\mathrm{~J} / \mathrm{g})$ & $\Delta H_{e}(\mathrm{~kJ} / \mathrm{eq})$ & ${ }^{\text {ther }} T_{g, 1}$ a $\left({ }^{\circ} \mathrm{C}\right)$ & ${ }^{\exp } T_{g, 1} \mathrm{~b}\left({ }^{\circ} \mathrm{C}\right)$ & ther $T_{g, 2}{ }^{\mathrm{c}}\left({ }^{\circ} \mathrm{C}\right)$ & ${ }^{\exp } T_{g, 2} \mathrm{~d}\left({ }^{\circ} \mathrm{C}\right)$ \\
\hline IPDI_r_0.2 & 40.4 & 56.7 & 376.4 & 131.9 & -21.2 & -18.8 & 60.4 & 54.6 \\
\hline IPDI_r_o.5 & 103.7 & 54.5 & 252.3 & 132.6 & 10.4 & 10.6 & 74.1 & 74.7 \\
\hline IPDI_r_0.8 & 159.2 & 49.4 & 56.7 & 70.8 & 57.8 & 57.8 & 91.3 & 92.9 \\
\hline HDI_r_0.2 & 17.3 & 23.7 & 356.2 & 122.5 & -27.1 & -36.4 & 52.2 & 52.6 \\
\hline HDI_r_0.5 & 40.1 & 19.6 & 272.5 & 135.9 & -7.4 & -3.3 & 51.4 & 52.9 \\
\hline HDI_r_0.8 & 63.4 & 17.8 & 108.0 & 120.7 & 21.5 & 28.3 & 50.5 & 48.7 \\
\hline
\end{tabular}

a $T_{g}$ value for the intermediate material calculated by the Fox Eq.

b Experimental $T_{g}$ value for the intermediate material determined by DSC.

c $T_{g}$ value for the final material calculated by the Fox Eq.

d Experimental $T_{g}$ value for the intermediate material determined by DSC.

For a given model and heating rate, the linear plot of the left-hand side of Eq. (10) versus $T^{-1}$ allowed us to obtain the average activation energy and average pre-exponential factor from the slope and the intercept. In this study, we chose the kinetic model with an activation energy similar to that obtained iso-conversionally (Eq. (9)) and with a good correlation coefficient in Eq. (10) (Coats-Redfern method).

The rate constant $k$ and the reaction rate $\mathrm{d} \alpha / \mathrm{d} t$ were calculated for each conversion from non-isothermal $E$, and $A$ data using the Arrhenius equation and Eq. (7) and the kinetic model, respectively.
Integrating Eq. (7) for isothermal experiments, we can obtain Eq. (11):

$\ln \mathrm{t}=\ln \left[\frac{\mathrm{g}(\alpha)}{\mathrm{A}}\right]+\frac{\mathrm{E}}{R T}$,

This equation relates, for each conversion, the temperature and the time of curing. The constant $\ln [g(\alpha) / A]]$ is directly related to the value $\ln [A R / g(\alpha) E]$ by $E / R$, which can be deduced from the non-isothermal adjustment (Eq. (9)), if isothermal and non-isothermal curing take place in the same conditions. In this work we used $\ln [A R / g(\alpha) E]$ and $E / R$ obtained by dynamic experiments and Eq. (9) to estimate the time of curing for both curing stages by using Eq. (11). 

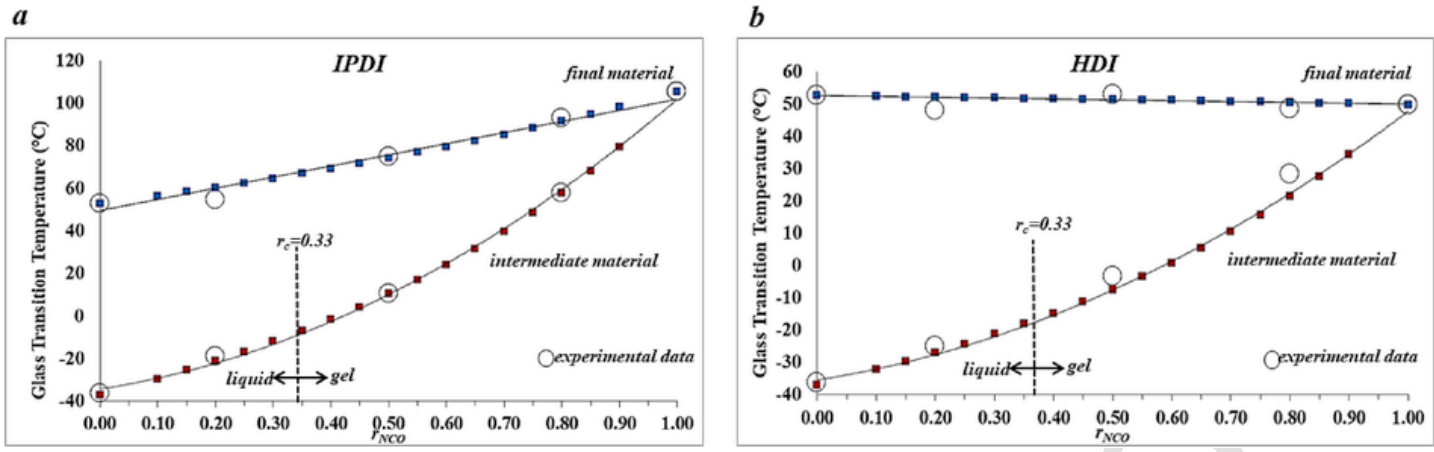

Fig. 6. Plot of experimental (circles) and calculated (full squares) $T_{g}$ s against $r_{N C O}$ for a) IPDI and b) HDI dual curing formulations.
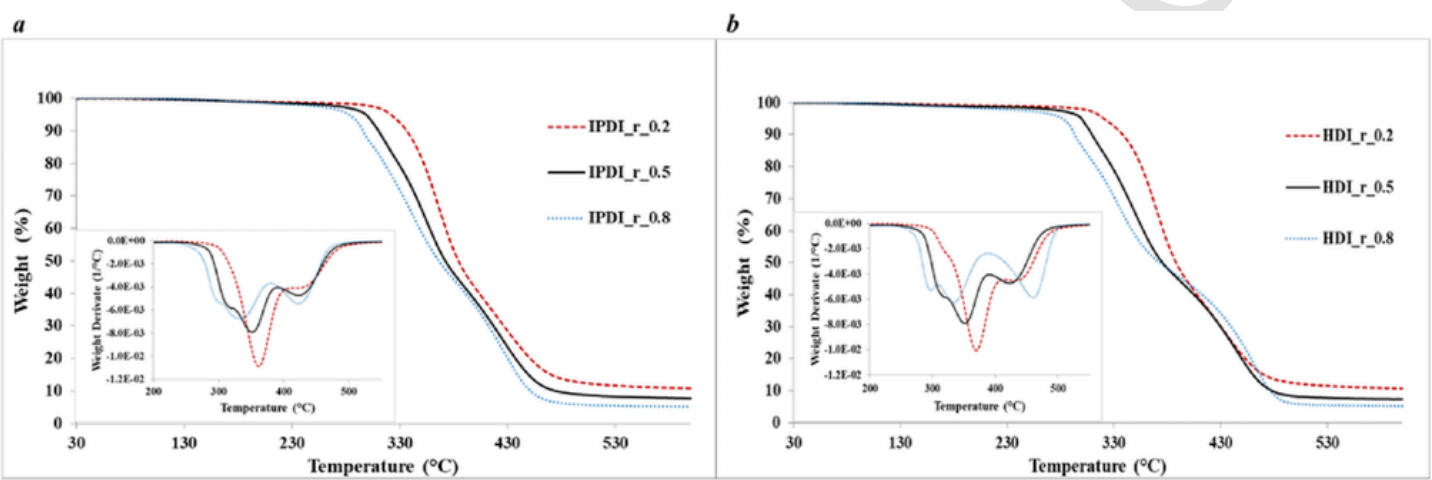

Fig. 7. TGA curves of a) IPDI and b) HDI thermosets with the different compositions selected. Insets show the rate of weight loss against temperature, DTGA.

Table 5

Thermogravimetric and thermomechanical data obtained for IPDI and HDI thermosets.

\begin{tabular}{|c|c|c|c|c|c|c|c|}
\hline Sample & $T_{2 \%}{ }^{\mathrm{a}}\left({ }^{\circ} \mathrm{C}\right)$ & $T_{\max }{ }^{\mathrm{b}}\left({ }^{\circ} \mathrm{C}\right)$ & Char Yield $\left({ }^{\circ} \mathrm{C}\right)$ & $F W H M^{\mathrm{d}}\left({ }^{\circ} \mathrm{C}\right)$ & $T_{\tan \delta}{ }^{\mathrm{e}}\left({ }^{\circ} \mathrm{C}\right)$ & $E^{\mathrm{f}}(\mathrm{MPa})$ & Young's Modulus ${ }^{g}(\mathrm{GPa})$ \\
\hline IPDI_r_0.2 & 287.6 & $362 / 446$ & 9.9 & 9.5 & 80.1 & 19.1 & 2.1 \\
\hline IPDI_r_o. 0.5 & 257.5 & $353 / 432$ & 7.3 & 13 & 104.7 & 18.9 & 2.5 \\
\hline IPDI_r_0.8 & 227.6 & $333 / 423$ & 4.8 & 13 & 129.4 & 18.8 & 3.2 \\
\hline HDI_r_0.2 & 299.7 & $369 / 442$ & 10.7 & 10 & 62.6 & 13.0 & 1.5 \\
\hline HDI_r_0.5 & 268.3 & $349 / 445$ & 7.4 & 9.5 & 66.0 & 13.5 & 1.7 \\
\hline HDI_r_0.8 & 217.3 & $333 / 460$ & 5.2 & 11.5 & 69.5 & 14.2 & 1.9 \\
\hline
\end{tabular}

a Temperature of $2 \%$ of weight loss.

b Temperatures of the maximum rate of degradation of the two main steps.

c Char residue at $600^{\circ} \mathrm{C}$.

d Full width at half maximum of $\tan \delta$ peak.

e Temperature of the maximum of $\tan \delta$ at $1 \mathrm{~Hz}$.

f Relaxed modulus determined at the $\mathrm{T} \tan \delta+40^{\circ} \mathrm{C}$ in the rubbery state.

$\mathrm{g}$ Young modulus determined at $30^{\circ} \mathrm{C}$ under flexural conditions.

$a$

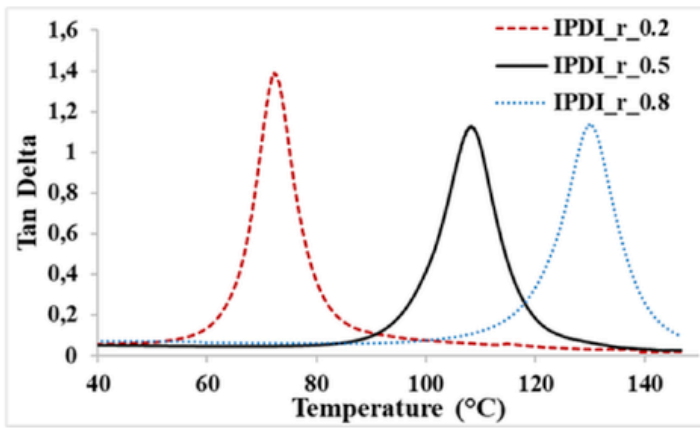

$b$

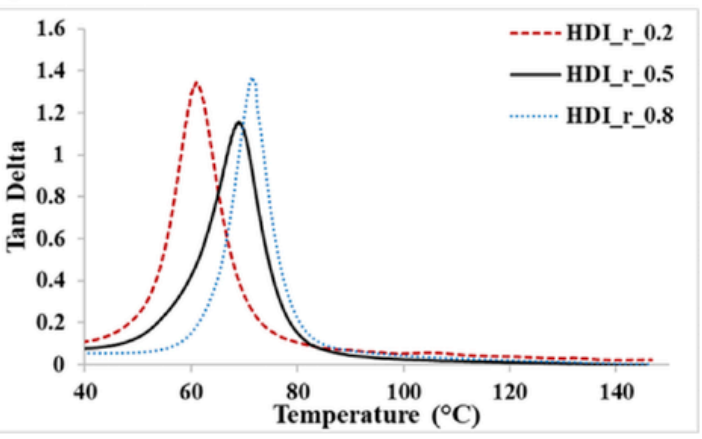

Fig. 8. Tan $\delta$ and storage modulus against temperature of IPDI (a) and HDI (b) thermosets. 


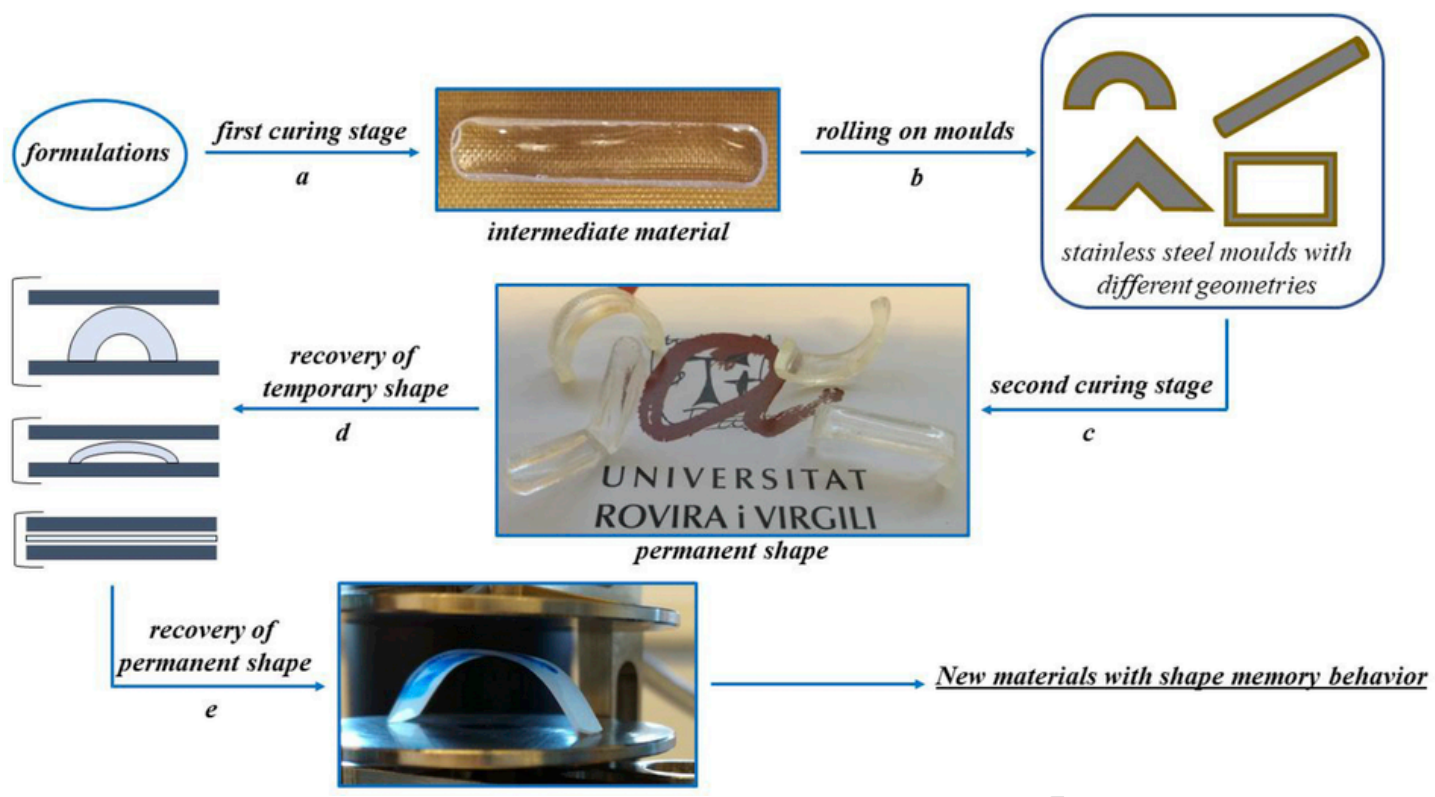

Fig. 9. Representation of the bent-shaped sample processing, shape memory programming and recovery process.

\section{RESULTS and DISCUSSION}

\subsection{Study of the dual curing by DSC and FTIR}

The sequential dual curing processes, their calorimetric kinetics and FTIR conversions were studied using a fixed $r_{N C O}$ equal to $0.5 e q_{N C O} / e q_{t}$.

With the aim to improve the sequential character of the dual curing system, we have studied the use of different proportions of $1 \mathrm{MI}$ as the catalyst (0.1-0.05-0.025 phr) for IPDI_r_0.5 (Fig. 1a) HDI_r_0.5 (Fig. 1b) systems by means DSC dynamic studies.

It can be observed, that as the catalyst proportion increases, the exotherm due to the first stage shifts at lower temperatures, and the curve is flattened and becomes difficult to clearly define and control the on-set and end-set temperatures of the isocyanate-thiol coupling. Due to the reactivity at low temperatures, this process starts while we are adding the isocyanate to the corresponding formulation. It is worth to note that in all the samples there is a sequential succession of curing steps with a clear separation between both peaks, due to isocyanate-thiol and epoxy-thiol click reactions, respectively. Furthermore, the separation between both steps increases as the amount of $1 \mathrm{MI}$ decreases, allowing to obtain an excellent control over the global curing process. If we compare the curves for IPDI and HDI curing processes, we can state that the separation between both processes is better in HDI formulations.

Table 2 collects the most characteristic calorimetric data of the curing of the samples studied in terms of heat reaction $(\Delta \mathrm{H})$ and temperature of the maximum of exothermic peak (Tpeak).

As we can see in the table, the heat released during the dynamic curing of the isocyanate-thiol reaction $\left(\Delta H_{N C O}\right)$ is always lower in HDI formulations than in IPDI. In addition, this value decreases on increasing the amount of $1 \mathrm{MI}$ in the formulation. These observations indicate that HDI is more reactive than IPDI and that the mixtures begin to react during the preparation, leading to a loss of enthalpy.

On the other hand, when we compare the enthalpies released in the thiol-epoxy reaction for both type of formulations, the values obtained are comparable. As expected, the temperature of the maximum of the peaks corresponding to both processes $\left(T_{\text {peak }}\right)$ increases on decreasing the proportion of $1 \mathrm{MI}$ in the formulation. Taking all of this into ac- count, we have selected as optimal catalyst loading for thiol-isocyanate-epoxy networks $0.025 \mathrm{phr}$ of $1 \mathrm{MI}$.

To obtain the kinetic parameters and the kinetic model, which best describes the reactive processes involved in our thiol-isocyanate-epoxy curing systems dynamic DSC experiments were performed.

Fig. 2 plots conversion against temperature, calculated according to Eq. (2), for isocyanate-thiol and epoxy-thiol reactions that occur at lower and higher curing temperatures, respectively, for IPDI_r_0.5 formulations at different heating rates $\left(2,5,10\right.$ and $\left.20^{\circ} \mathrm{C} / \mathrm{min}\right)$. In Supporting Information, Fig. S1 reports the same study for HDI_r_0.5 formulations.

The kinetic parameters of non-isothermal curing for both curing stages obtained by DSC dynamic experiments are reported in Table 3 for IPDI_r_ 0.5 formulations. The results obtained for HDI_r_0.5 formulations are collected in Table S1 (Supporting Information).

From Table 3 it is possible to observe that the activation energy remains, during both curing stages, relatively constant. This result suggests that the reaction mechanism is the same in the whole range of curing, according to the click character of the reaction, and a single kinetic model is only needed to describe the curing. In many reaction processes the values of activation energy, due to the compensation effect between the activation energy and the pre-exponential factor, do not reflect exactly the reaction rate and it is better to discuss the rate constants calculated using Eq. (7) and the kinetic model [32].

In accordance with the Coats-Redfern method described in the theoretical section, various kinetic models have been studied: diffusion $\left(D_{1}, D_{2}, D_{3}\right.$, and $\left.D_{4}\right)$, Avrami-Erofeev $\left(A_{2}, A_{3 / 2}, A_{3}\right.$, and $\left.A_{4}\right)$, power law, phase-boundary-controlled reaction $\left(R_{2}\right.$ and $\left.R_{3}\right)$, autocatalytic ( $n+m=1,2$ and 3), and order $\mathrm{n}(n=1,2$ and 3) [33]. We have found that all the systems studied follow at all heating rates an Avrami-Erofeev model $\mathrm{A}_{3}$ (first curing stage) and $\mathrm{A}_{4}$ (second curing stage). Although there is no reason for some of these models to have any physicochemical meaning in the curing processes, they can still be used to aid to the description of the calorimetric curve.

Table 3 also highlights the dual nature of the system studied since isocyanate-thiol coupling shows rate constants about fifteen times greater than epoxy-thiol reaction. HDI_r_0.5 shows the same behaviour, but in a more pronounced way (see Table S1). Furthermore, it can be observed than the rate constant increases with the conversion, and after reaching a maximum, decreases in accordance with the autocat- 
alytic nature of both curing stages. It is well known, that $\mathrm{OH}$ groups catalyzes the nucleophilic attack to the epoxides, due to the hydrogen bonding between hydroxylic protons, formed during the reaction, and the epoxides, facilitating the opening of the ring [34]. The attack of the thiol to the isocyanate can be also catalysed by the formation of hydrogen bonding, increasing the electrophilic character of the isocyanate group.

DSC dynamic studies provide information about the heat evolved in the overall reaction process but not about the elemental reactions that occur during curing. An interesting way to obtain structural information about the dual process is to monitor isothermal curing by means of FTIR spectroscopy. In this way, detailed data about the curing methodology can be obtained by determining the evolution of the absorption bands of the isocyanate and epoxide groups. This method allows the determination of the conversion progress at several reaction times for the different functional groups reacting during the curing process. As an example, Fig. S2 in Supporting Information shows some representative FTIR spectral regions collected during a) the first stage at $60^{\circ} \mathrm{C}$ and b) the second stage at $120^{\circ} \mathrm{C}$ of HDI_r_0.5 formulation. It can be observed the complete disappearance of the characteristic absorbance peaks of free isocyanate groups at $2280 \mathrm{~cm}^{-1}$ and epoxies at $915 \mathrm{~cm}^{-1}$.

According to DSC results, we found in both formulations that the conversion was complete at the end of both curing stages, indicated by a fractional conversion of 0.5 and 1 at the end of stage 1 and stage 2, respectively.

DSC gives information about the global advancement of the curing process, but the evolution of the functional groups during curing and the structure of the network formed needs to be observed by FTIR spectroscopy. Fig. 3 shows the evolution of the bands of the reactive groups during the first and second stages of the curing for the HDI_r_0.5 mixture.

As we can see, in the first curing stage the isocyanate band completely disappears after $5 \mathrm{~min}$ of reaction at $60^{\circ} \mathrm{C}$ (red arrow), while thiourethane absorptions at 1670 and $3350 \mathrm{~cm}^{-1}$ are formed (blue arrows), indicating that the complete formation of thiourethane has been achieved. The mixture with IPDI reacts more slowly as can be seen in Fig. S3 and a reaction time of $30 \mathrm{~min}$ is needed for the complete disappearance of the isocyanate band. In the second stage of curing hydroxyl absorptions appear during the process, while the epoxy band at $915 \mathrm{~cm}^{-1}$ disappears. The second stage is finished in $60 \mathrm{~min}$ for both mixtures. Thiol absorptions at $2580 \mathrm{~cm}^{-1}$ can be detected but their evolution can be only followed from a qualitative point of view, due to its weak intensity. The peak at $1730 \mathrm{~cm}^{-1}$ attributed to the carbonyl absorption of ester groups of the S4 does not experiment any change during the curing process and has been used as internal reference for kinetic studies.

Several authors reported the formation of oxazolidone moieties in the curing of mixtures of isocyanate and epoxide [35,36]. This reaction also leads to the formation of isocyanurate groups by cyclization of isocyanates. In a previous study, we could state that isocyanurate were formed at lower temperatures than oxazolidone moieties [36]. This indicates that the formation of isocyanurate rings could occur in the first stage of the curing of the dual process but the temperature is too low to allow the oxazolidone moiety to be formed. Both reactions can be catalysed either by amines or by Lewis acids. In the FTIR spectra of the intermediate (Fig. 3a) and final material (Fig. 3b) no absorptions at $1715 \mathrm{~cm}^{-1}$, typical of isocyanurate rings, nor absorptions at $1750-1740 \mathrm{~cm}^{-1}$, indicative of oxazolidone formation, can be observed. This indicates that in the first stage of curing, in which isocyanate, thiol and epoxy groups coexist, the reaction of isocyanate and thiol is favoured, confirming its click character. In the second stage, the formation of oxazolidones cannot occur, since there is no unreacted isocyanate in the reactive mixture.
Fig. 4 shows the FTIR conversion plot during isothermal curing at $60^{\circ} \mathrm{C}$ (isocyanate-thiol click reaction) and later at $120^{\circ} \mathrm{C}$ (epoxy-thiol click reaction) for IPDI_r_0.5 and HDI_r_0.5 samples. The temperature of the first and second stages have been chosen according to DSC analyses and the isothermal reaction times, tentatively, estimated by using Eq. (11) and the isoconversional non-isothermal kinetic parameters previously determined (Tables 3 and S1).

From the FTIR and DSC studies, it is evident that the first curing stage is faster for HDI formulations that for IPDI mixtures, as observed in a previous study, whereas the second stage is not affected by the isocyanate used in the formulation [16].

Although the curing times for both curing stages can be easily calculated from the kinetic studies, the preparation of samples for DMTA in a metal mould in the oven requires longer times and the optimization of the curing schedule is always needed. Thus, by registering FTIR and DSC curves at different curing times, we have optimized the curing schedule to achieve complete conversion of isocyanate and epoxy groups at the end of both stages. The optimized curing schedule is: i) stage 1 at $60^{\circ} \mathrm{C}$ for $1 \mathrm{~h}$ in the case of IPDI and for $40 \mathrm{~min}$ with $\mathrm{HDI}$; ii) stage 2 at $120^{\circ} \mathrm{C}$ for $2 \mathrm{~h}$ for both systems studied. The curing times and temperatures reported here have been used for the preparation of thermosets with different compositions based on IPDI and HDI.

In order to know the influence of the composition of the formulation in the dual curing behaviour, we extend the calorimetric study to isocyanate contents 0.2 and 0.8 . In Fig. 5, the DSC curves for a) IPDI and b) HDI formulations showing the exotherms corresponding to each curing stage are represented.

As we can see in the figure, on increasing the isocyanate content (from $r_{N C O} 0.2$ to 0.8 ) the first curing stage shifts at higher temperatures whereas the second stage remains almost unchanged. This result suggests that an excess of thiol favours the nucleophilic thiol isocyanate reaction, but the network formed during first stage does not modify significantly the kinetics of the epoxy-thiol reaction. It should be noticed, that in all the formulations, in the second stage the epoxy-thiol proportions are stoichiometric. Although, all formulations are characterized by a sequential succession of curing steps with a separation between both reaction peaks, in the case of IPDI_r_0.8 sample the separation between the curing stages is not clearly defined. This indicates that formulations with proportions of IPDI 0.8 or higher are not adequate for applications requiring sequentiality. It can be also stated that a better sequential dual-curing behaviour is obtained with epoxy-rich formulations.

The contribution of both isocyanate-thiol and epoxy-thiol reactions in terms of reaction heat for all the formulations prepared is reported in Table 4.

In a previous study in the latent catalysed curing of thiols and IPDI we determined an enthalpy by equivalent of $72 \mathrm{~kJ} / \mathrm{eq}$ [16]. In the present study, the heat released by equivalent is lower. This is because this reaction begins at room temperature during the preparation of the reactive mixture and some heat get lost before DSC experiment. The higher reactivity of HDI leads to lower values of enthalpy released. It is reported that thiol-epoxy reactions release about $125 \mathrm{~kJ}$ per equivalent of epoxide [37]. As we can see in Table 4, the thiol-epoxy reaction seems to be complete for all the formulations, with the exception of IPDI_r_0.8 in which a partial overlapping of both reactions occurs, which difficult the selection of the base-line. Thus, the measured heat released confirms the sequential dual character of these curing systems, except for IPDI_r_0.8 mixture.

\subsection{Thermal and dynamo mechanical characterization}

By using the Fox copolymer rule (Eqs. (3) and (4))) we are able to predict the $T_{g} s$ of intermediate and final materials as function of the formulation composition, using the experimental $T_{g}$ data of the un- 
cured epoxy-thiol formulation, which is $T_{g(e-t)}^{0}=-37.3^{\circ} \mathrm{C}$ and the $T_{g} \mathrm{~S}$ of the pure thermosets: i) IPDI-thiol $T^{\infty}{ }_{g(I P D I-t)}=105.4^{\circ} \mathrm{C}$; ii) HDI-thiol, $T_{g(H D I-t)}^{\infty}=49.8^{\circ} \mathrm{C}$ and iii) epoxy-thiol, $T_{g(e-t)}^{\infty}=52.6^{\circ} \mathrm{C}$.

Experimental $T_{g}$ values have been determined by DSC in the intermediate and final curing stages. The values of experimental and calculated $T_{g}$ s are collected in Table 4 for all the formulations studied. Fig. 6 shows the dependence of the calculated and experimental $T_{g} \mathrm{~s}$ in function of the different $r_{N C O}$ compositions for a) IPDI and b) HDI mixtures. The theoretical critical gelation ratio, $r_{c}$, has been calculated by the Flory-Stockmayer theory (Eq. (1)).

As can be seen in Fig. 6, a wide range of intermediate and final materials could be obtained using IPDI and HDI as isocyanates and different formulation compositions. Furthermore, there is a significant influence of the type of isocyanate on the intermediate and final $T_{g} s$, and the material properties, in particular in the final stage. Whereas IPDI fully cured thermosets show a great variation of the $T_{g}$ with the composition (from 52.6 to $105.4^{\circ} \mathrm{C}$ ), all the HDI thermosets have similar values. This is caused by the similar $T_{g}$ values of the pure HDI-thiol and epoxy-thiol thermosets, 49.8 and $52.6{ }^{\circ} \mathrm{C}$, respectively. Calculated and experimental $T_{g} s$ fully agree, especially for IPDI formulations, which indicates that the reactions implied occurred completely, without side-reactions, as expected from click processes.

Keeping in mind the value of $r_{c}$ of 0.33 it is possible to obtain a gelled and therefore solid-like and shape-conformable intermediate materials, after the first stage, for compositions with $r_{N C O}>0.33$ at compositions lower than this value, the material will be viscous with high adhesion properties.

The thermal stability of the thermosets was evaluated by thermogravimetry. Fig. 7 shows the TGA curves for all formulations studied and the insets show the rate of weight loss against temperature (DTGA curves). The main data obtained for these experiments are collected in Table 5.

It can be observed that the degradation takes place in two principal steps, with a small shoulder at lower temperature of the first degradation step, which increases with the proportion of isocyanate in the formulation. The first stage, at the temperature range of $280-400{ }^{\circ} \mathrm{C}$, is characterized by the decomposition of thiourethane segments and it is reasonable to assume that the formation of the shoulder is significantly affected by the $r_{N C O}$ chosen [38]. In a previous work of our group, based in poly(thiourethane) networks, a complex degradation mechanism with three different steps was observed [16]. Thus, on increasing the amount of these structures in the global network, the DTGA curves tend to become more complex with the clear appearance of a shoulder. The second degradation step, occurring at the temperature range $400-500^{\circ} \mathrm{C}$, can be attributed to the degradation of hydroxy-thioether structures but also to the poly(thiourethane) structure [8]. This is evident if we compare the temperatures of the maximum rate of weight loss, higher in case of HDI thermosets, as seen in our previous study [16]. However, it should be pointed out that both degradation steps are strongly overlapped, and therefore it is not possible to attribute exclusively the first peak to the thiourethane structure and the second to the thiol-epoxy network. It must be considered that the thiol monomer randomly interconnects both types of networks, which are not independent each other. The overall thermal behaviour of the samples prepared is then the result of the different stability of the chemical bonds formed during the first and the second stage.

From the values of the table we can see that the higher the proportion of poly(thiourethane) fragments in the network the lower the thermal stability of the material. This is reflected in the initial degradation temperatures $\left(T_{2 \%}\right)$ and in the temperature of the maximum rate of degradation $\left(T_{\max }\right)$. IPDI thermosets presents a higher thermal stability than their HDI analogue. The presence of aromatic rings in the epoxy compound leads to a higher char yield in the thermosets with a higher proportion of DGEBA.
The thermomechanical behaviour of all the materials prepared was evaluated by DMTA analyses. Fig. 8 presents the $\tan \delta$ curves obtained for both types of materials. The main data extracted from DMTA tests are collected in Table 5. As we can see in Fig. 8, the materials obtained are homogeneous with unimodal and narrow shapes despite the dual curing procedure applied in the preparation. The values of the width of the curve at half height ( $F W H M$ ) are rather small, according to the click character of the curing reactions implied, without the formation of unexpected structures, and they are consistent with the ones reported by Gamardella et al. for pure thiol-isocyanate thermosets [16]. The high homogeneity of these materials and their narrow ranges of relaxation make these materials applicable to smart technologies and as shape memory materials, as for example in actuators, valves, robotics and optical applications, etc. [39-42].

The values of the temperature of the maximum of $\tan \delta$ depend fundamentally on the structure of the isocyanate monomer, rigid and compact, in the case of IPDI, and flexible and linear for HDI. In the case of IPDI-based thermosets, the temperature of the maximum of $\tan \delta$ increases as $r_{N C O}$ increases, due to the high compactness and rigid structure of IPDI monomer and the possibility to enhance interactions between chains by hydrogen bonding. On the other side, with HDI samples, $\tan \delta$ temperatures remain almost similar, in agreement with the trends observed by DSC measurements. The values obtained are a little lower than those obtained in pure poly(thiourethane) thermosets previously reported [16]. Furthermore, for all the samples studied the height of $\tan \delta$ curve is comparable for all the thermosets.

There are no significant differences in the $E^{\prime}$ data for the IPDI samples prepared, but this value tends to decrease on increasing the amount of HDI in the material. Finally, the Young's modulus yields the highest values in the case of IPDI materials, due to their rigid network structure. Young moduli slightly increase on increasing the isocyanate content, due to the higher rigidity of poly(thiourethane) networks, which is enhanced by the presence of hydrogen bonding between chains.

\subsection{Prospective applications}

In this paragraph, we illustrate some possible applications of the prepared samples in the field of materials with shape memory behaviour. IPDI_r_0.5 and HDI_r_0.5 samples were chosen as representative samples. As shown in Fig. 9, IPDI and HDI formulations, prepared as described in the experimental part, were poured into a Teflon mould and cured at $60^{\circ} \mathrm{C}$ for $40 \mathrm{~min}$ in the case of HDI samples and for $60 \mathrm{~min}$ in the case of IPDI materials (1st curing stage) to obtain intermediate prismatic shape materials (step $a$ ). Thanks to the deformability of these gelled intermediate materials, they were easily rolled onto stainless steel moulds having different geometries and covered with a Teflon layer (step $b$ ) obtaining bent-shaped surfaces. To obtain permanent shapes, the samples were heated up at $120^{\circ} \mathrm{C}$ for $120 \mathrm{~min}$ (2nd curing stage), cooled at room temperature and peeled off from the moulds (permanent shapes, step $c$ ).

The shape memory characterization consists of two steps: i) programming of temporary shape and ii) recovery of the original shape. The first step was performed between two stainless steel plates at $150{ }^{\circ} \mathrm{C}$ (programming temperature) applying enough pressure to flatten the sample (step $d$ ). They were cooled down quickly to room temperature and the resulting material showed a prismatic flat shape. In the second step, once the temporary shape was programmed, the recovery of the original permanent bent shape was conducted by heating the samples at $120^{\circ} \mathrm{C}$ (step $e$ ). Since the results obtained seems to be highly promising, the complete study of the shape memory behaviour of the new materials prepared in this work will be carried out in future projects to explore their possible applications. 


\section{Conclusions}

In this work, a new family of thermosets based on thiol-isocyanate-epoxy networks was developed by means of a dual curing process and exploiting the use of two different aliphatic isocyanates, isophorone diisocyanate and hexamethylene diisocyanate. The sequential dual character of this new curing system relies on the faster reaction kinetic of the isocyanate-thiol coupling that occurs at a relatively low temperature, compared to the epoxy-thiol reaction between the remaining thiol groups and the epoxy, taking place at higher temperature. The click character of both reactive processes prevent other side reactions to occur. The extent of the first curing step is controlled by the equivalent ratio between the isocyanate and thiol, which also tailors the intermediate and final materials properties. Therefore, it is possible to design intermediate materials, which can be gels or viscous liquids, depending on the proportion of isocyanate, and fully cured materials, which can be loosely or tightly crosslinked. The characteristics of the intermediate materials open the possibility to be used as adhesives or to be conformed to create complex shapes that can be further crosslinked. Furthermore, the materials prepared show an interesting shape memory behaviour that will be further studied, and which opens the possibility to be applied in smart technologies.

\section{Conflicts of interest}

There are no conflicts to declare.

\section{Acknowledgments}

The authors would like to thank MCIU (Ministerio de Ciencia, Innovación y Universidades) and FEDER (Fondo Europeo de Desarrollo Regional) (MAT2017-82849-C2-1-R and MAT2017-82849-C2-2-R) and to Generalitat de Catalunya (2017-SGR-77) for the financial support.

\section{Appendix A. Supplementary data}

Supplementary data to this article can be found online at https:// doi.org/10.1016/j.polymer.2019.04.041.

\section{References}

[1] I. Hamerton, J. Kratz, in: Guo (Ed.), Thermosets. Structure, Properties, and Applications Q, Elsevier, Amsterdam, NL, 2018, pp. 303-326.

[2] J. Verrey, M.D. Wakeman, V. Michaud, J.-A.E. Månson, Composites Part A 37 (2006) 9-22.

[3] M. Giordano, A. Laudati, M. Russo, J. Nasser, G.V. Persiano, A. Cusano, Thin Solid Films 450 (2004) 191-194.

[4] X. Luo, P.T. Mather, ACS Macro Lett. 2 (2013) 152-156.
[5] D.P. Nair, N.B. Cramer, M.K. McBride, J.C. Gaipa, R. Shandas, C.N. Bowman, Polymer 53 (2012) 2429-2434.

[6] A. Belmonte, C. Russo, V. Ambrogi, X. Fernández-Francos, S. De la Flor, Polymers 9 (2017) 113-132.

[7] M. Sangermano, W. Carbonaro, G. Malucelli, A. Priola, Macromol. Mater. Eng. 293 (2008) 515-520.

[8] X. Fernández-Francos, A.O. Konuray, A. Belmonte, S. De La Flor, À. Serra, X. Ramis, Polym. Chem. 7 (2016) 2280-2290.

[9] P.T. Mather, X. Luo, I.A. Rousseau, Annu. Rev. Mater. Res. 39 (2009) 445-471.

[10] S.H. Cho, S.R. White, P.V. Braun, Adv. Mater. 21 (2009) 645-649.

[11] A.M. Prenen, J.C.A.H. Van der Werf, C.W.M. Bastiaansen, D.J. Broer, Adv. Mater. 21 (2009) 1751-1755.

[12] Y. Huang, G.T. Paloczi, A. Yariv, C. Zhang, L.R. Dalton, J. Phys. Chem. B 108 (2004) 8606-8613.

[13] B. Jaffrennou, N. Droger, F. Méchin, J.L. Halary, J.P. Pascault, E-Polymers 5 (2005) 1-19.

[14] Z.S. Petrović, J. Ferguson, Prog. Polym. Sci. 16 (1991) 695-836.

[15] J. Shin, J. Lee, H.M. Jeong, J. Appl. Polym. Sci. 135 (2018) 1-8.

[16] F. Gamardella, X. Ramis, S. De la Flor, À. Serra, React. Funct. Polym. 134 (2019) 174-182.

[17] O.D. McNair, B.J. Sparks, A.P. Janisse, D.P. Brent, D.L. Patton, D.A. Savin, Macromolecules 46 (2013) 5614-5621.

[18] J. Shin, H. Matsushima, C.M. Comer, C.N. Bowman, C.E. Hoyle, Chem. Mater. 22 (2010) 2616-2625.

[19] H. Matsushima, J. Shin, C.N. Bowman, C.E. Hoyle, J. Polym. Sci. Part A Polym. Chem. 48 (2010) 3255-3264.

[20] A. Belmonte, X. Fernández-Francos, À. Serra, S. De La Flor, Mater. Des. 113 (2017) 116-127.

[21] S. Vyazovkin, N. Sbirrazzuoli, Macromol. Rapid Commun. 21 (2000) 85-90.

[22] T.G. Fox, Bull. Am. Phys. Soc. 1 (1956) 123-132.

[23] E. Papadopoulos, M. Ginic-Markovic, S. Clarke, Macromol. Chem. Phys. 209 (2008) 2302-2311.

[24] R. Thomas, C. Sinturel, J. Pionteck, H. Puliyalil, S. Thomas, Ind. Eng. Chem. Res. 51 (2012) 12178-12191.

[25] S. Ye, N.B. Cramer, I.R. Smith, K.R. Voigt, C.N. Bowman, Macromolecules 44 (2011) 9084-9090.

[26] S. Vyazovkin, Isoconversional Kinetics of Thermally Stimulated Processes, Springer, New York, NY, USA, 2015166-231.

[27] S. Vyazovkin, N. Sbirrazzuoli, Macromol. Chem. Phys. 200 (1999) 2294-2303.

[28] A.W. Coats, J.P. Redfern, Nature 201 (1964) 68-69.

[29] H.E. Kissinger, Anal. Chem. 29 (1957) 1702-1706.

[30] R.L. Blaine, H.E. Kissinger, Thermochim. Acta 540 (2012) 1-6.

[31] S. Vyazovkin, D. Dollimore, J. Chem. Inf. Model. 36 (1996) 42-45.

[32] S. Vyazovkin, C.A. Wight, Annu. Rev. Phys. Chem. 48 (1997) 125-149.

[33] X. Ramis, J.M. Salla, J. Puiggalí, J. Polym. Sci. Part A Polym. Chem. 43 (2005) 1166-1176.

[34] B.A. Rozenberg, Adv. Polym. Sci. 75 (1986) 113-165.

[35] A. Bakry, R. Aversano, L. D'Ilario, V. Di Lisio, I. Francolini, A. Piozzi, A. Martinelli, J. Appl. Polym. Sci. 133 (2016) 1-8.

[36] M. Flores, X. Fernández-Francos, J.M. Morancho, À. Serra, X. Ramis, J. Appl. Polym. Sci. 75 (2012) 2779-2789.

[37] D. Guzmán, X. Ramis, X. Fernández-Francos, À. Serra, RSC Adv. 75 (2015) 101623-101633.

[38] M. Rogulska, A. Kultys, E. Olszewska, J. Therm. Anal. Calorim. 114 (2013) 903-916.

[39] T. Hisaaki, H. Hisashi, Y. Etsuko, H. Shunichi, Smart Mater. Struct. 5 (1996) 483-491.

[40] B. Yang, W.M. Huang, C. Li, C.M. Lee, L. Li, Smart Mater. Struct. 13 (2004) 191-195.

[41] Y. Yang, Y. Chen, Y. Li, M.Z.Q. Chen, Y. Wei, Soft Robot. 4 (2017) 147-162.

[42] B.S. Lee, B.C. Chun, Y.C. Chung, K.I. Sul, J.W. Cho, Macromolecules 34 (2001) 6431-6437. 